\title{
DAYA DUKUNG WISATA MANGROVE WONOREJO DI KOTA SURABAYA BERDASARKAN ASPEK FISIK, LINGKUNGAN DAN EFEKTIFITASNYA
}

\author{
Siti Nuurlaily Rukmana1), Meity Handiwati²) \\ ${ }^{12)}$ Program Studi Perencanaan Wilayah dan Kota, Universitas PGRI Adi Buana Surabaya \\ Email : nuurlaily_rukmana@unipasby.ac.id
}

\begin{abstract}
Abstrak
Wisata Mangrove Wonorejo merupakan wisata alam yang terletak di bagian timur Pantai Surabaya (PAMURBAYA) mempunyai luas area \pm 9 Ha. Potensi mangrove sebagai ekowisata memiliki produk wisata unggulan yang dapat dikembangkan melalui pengelolaan sumberdaya pariwisata yang ada. Tujuan penelitian ini adalah untuk mengetahui daya dukung wisata mangrove Wonorejo yaitu jumlah kapasitas maksimal wisatawan yang dapat ditampung di wisata mangrove Wonorejo. Metode penelitian yang digunakan adalah metode deskriptif kuantitatif dan teknik analisa perhitungan daya dukung wisata (PCC, RCC, ECC). Berdasarkan hasil penelitian didapatkan persamaan PCC $>$ RCC $\geq$ ECC dengan nilai $3510>380 \geq 244$, artinya objek tersebut masih dapat menampung jumlah wisatawan per hari atau masih dalam standart.
\end{abstract}

Kata kunci: Daya Dukung Wisata, Jumlah Kunjungan per Hari, Wisata Mangrove Wonorejo

\begin{abstract}
Wonorejo Mangrove Tour is a natural tourism, located in the eastern part of Surabaya Beach (PAMURBAYA) has an area of $\pm 9 \mathrm{Ha}$. The potential of mangrove as ecotourism has a superior tourism product that can be developed through the management of existing tourism resources. The aim of this research is to find out the tourism carrying capacity of Wonorejo mangrove tour, they are capacity the number of tourist maximum that is able to be accommodate by Wonorejo mangrove tourism. The method used is descriptive quantitative research method and analysis technique by calculation of tourism carrying capacity (PCC, RCC, and ECC). Based on the research result obtained equation $P C C>R C C \geq E C C$ with a value of $3510>380 \geq 244$, meaning that the object is able accommodate the number of tourist per day or still in standard
\end{abstract}

Keywords: Number of visit Per Day, Tourism Carrying Capacity, Wonorejo Mangrove Tourism

\section{PENDAHULUAN}

Kota Surabaya jika dilihat dari kondisi geografinya yaitu di pantai timur Surabaya memiliki wisata alam yang cukup indah, dan dikenalnya sebagai ekowisata mangrove Wonorejo. Hal ini dibuktikan dengan meningkatnya jumlah wisatawan sebesar 2,9\% pada tahun 2017-2018 (DKPP, 2019). Meningkatnya angka wisatawan mendefiniskan tingkat kepuasan tempat wisata tersebut memiliki dampak positif bagi penggunanya (Cerina et al, 2011). Tingkat kepuasan wisatawan dalam berkunjung ini tentunya dikarenakan adanya atraksi pada wisata tersebut. Seperti yang dijelaskan oleh (Kostopoulou, 2018) menyebutkan bahwa pariwisata kreatif harus memiliki atrasi yang unik dan menjadi karakteristik daerah masingmasing. Beragam jenis biota dan fauna yang ada di dalamnya menambah jumlah tanaman mangrove, sehingga sering disebut wisata ecotourism dan edu-tourism (Nurdin, 2011). Konsep eco-tourism sudah dikenalkan sejak tahun 80-an yang merupakan kependekan dari ekologi wisata atau ekowisata sedangkan konsep edu-tourism terfokus pada tempat wisata yang bisa memberikan 
informasi/pengetahuan terhadap masyarakat yang berkaitan dengan hutan wisata mangrove wonorejo.

Selaras dengan penelitian sebelumnya (Wahyuni, Sulardiono, \& Hendrarto, 2015) keunggulan wisata mangrove wonorejo di keragaman mangrove dan burung. Selain itu juga disebutkan dalam penelitian sebelumnya bahwa pengembangan ekowisata mangrove wonorejo bertumpu pada 4 kekuatan (Umam, Tjondro Winarno, \& Sudiyarto, 2015) yaitu kesesuaian ekologi, keragaman vegetasi, promosi dan dukungan pemerintah. Hal ini tentunya memberikan peluang yang ada di wisata wonorejo yaitu salah satu tempat wisata yang diminati oleh masyarakat sehingga mendapat dukungan penuh oleh pemerintah. Namun keberadaan wisata mangrove Wonorejo juga memiliki kelemahan (seperti sering terjadi perangkapan kerja, keramahan pengelola masih kurang, kebersihan kurang terjada dan ancaman (seperti pesaing yang sejenis, penebangan hutan mangrove secara liar, dan kerusakan yang dilakukan pengunjung/wisatawan.
Wisata mangrove Wonorejo yang terletak di bagian timur pantai Kota Surabaya ini memiliki keunikan tersendiri, yaitu memiliki keanekaragaman hayati. Seperti yang dijelaskan pada penelitian sebelumnya (Murtini, 2017) bahwa menunjukkan kesesuain ekowisata di kawasan mangrove memperoleh nilai 66 dengan kriteria sesuai, yang artinya kawasan mangrove wonorejo sesuai untuk dikembangkan kawasan ekowisata dan kawasan edukasi. Sehingga berdasarkan beberapa penelitian sebelumnya, maka yang menjadi penelitian sebelumnya adalah analisis daya dukung wisata didsasarkan dengan tiga aspek yaitu fisik (PCC), riil (RCC) dan efektif (ECC). Pada penelitian ini memiliki perbedaan dengan penelitian sebelumnya yaitu pada metode analisis untuk menghitung daya dukung wisata

\section{METODE}

Penelitian ini berkaitan dengan daya dukung wisata di wisata Mangrove Wonerejo, Surabaya dengan luas \pm 9Ha (Gambar 1).

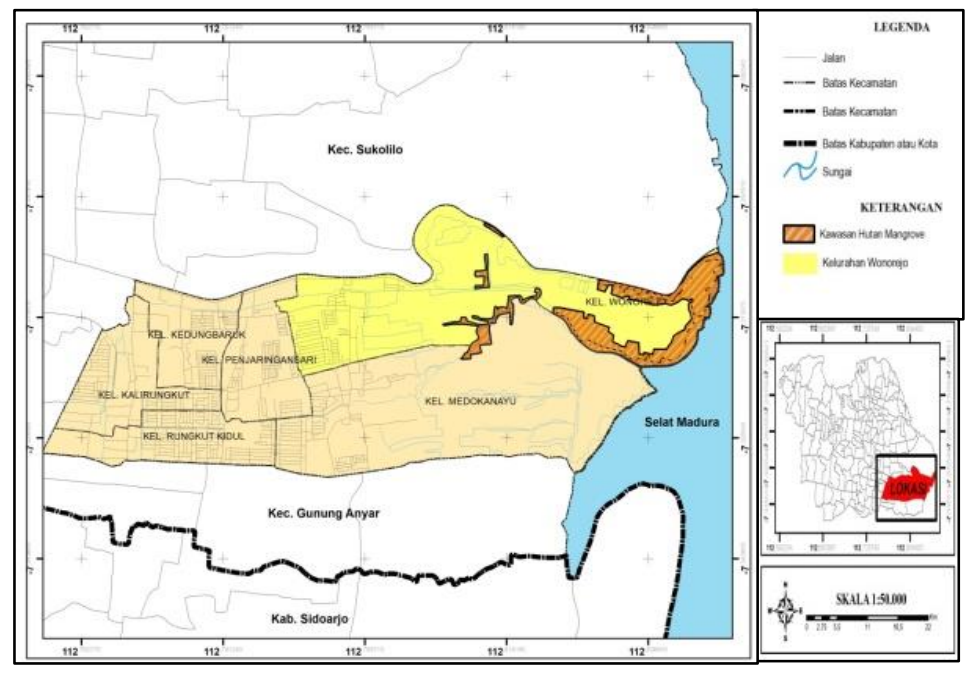

Gambar 1 Peta Wilayah Studi

\begin{abstract}
Pendekatan penelitian yang digunakan adalah deskriptif kuatitatif dengan menjabarkan data-data fisik dan non fisik. Proses penelitian ini dilakukan selama lima (5) bulan. Metode pengumpulan data
\end{abstract} menggunakan data primer dan data sekunder. Metode analisis yang digunakan untuk menganalisis daya dukung wisata yaitu

\section{a. Daya Dukung Fisik (Physical Carrying Capacity/PCC)}

Daya dukung fisik/PCC merupakan jumlah maksimum wisatawan yang secara fisik dapat terpenuhi di suatu kawasan dalam satu satuan waktu tertentu (Fendeli, 2009) dengan perhitungan: 


$$
P C C=A \times \frac{1}{B} \times R f
$$

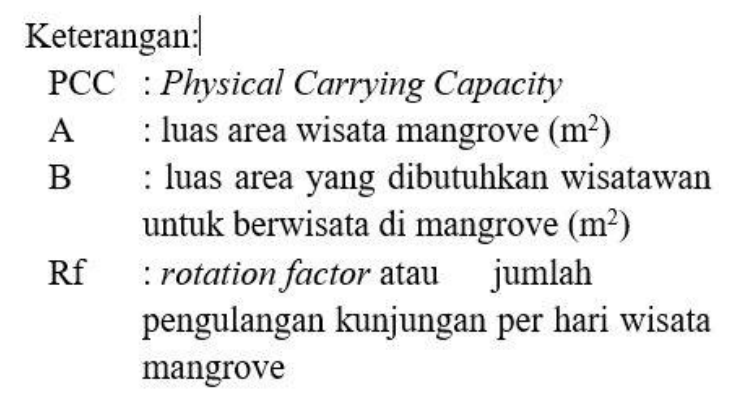

b. Daya Dukung Riil (Real Carrying Capacity/RCC)

Perhitungan daya dukung PCC ini dimulai dari jumlah kunjungan, kemudian menghitung faktor koreksi berdasarkan karakteristik kawasan sebagai pertimbangan variable biofisik, seperti:

a) Diversitas biotik $\left(\mathrm{Cf}_{1}\right)$
Diversitas biotik ini disesuaikan dengan flora-fauna yang ada (ex. Burung,mamalia, invetebrata, ikan dan herpertofauna). Jumlah fauna di sekitar mangrove wonorejo memiliki radius 100 meter. Berikut Indeks Diversitas Simpson (IDS)

$$
\begin{gathered}
\lambda=\frac{\sum n i(n i-1)}{N(N-1)} \\
I D=1-\lambda
\end{gathered}
$$

Dimana:

ID : indeks diversitas

ni : jumlah individu jenis $\mathrm{i}$

$\mathrm{N} \quad$ : jumlah individu seluruh jenis

Kisaran nilai indeks Simpson adalah 0-1, semakin mendekati 0 nilai ID suatu komunitas, maka semakin rendah diversitas/ keberagamannya (Muta'ali, 2015)

b) Kelerengan (Cf2)

Kelerengan disini di dasarkan pada Surat Keputusan Menteri Pertanian No. 83/ KPTS/ UM/ 11/ 1980 No. 638/ KPTS/ UM/ 8/ 1981,

\begin{tabular}{|l|l|l|l|}
\hline $\begin{array}{l}\text { Kelas } \\
\text { Lereng }\end{array}$ & $\begin{array}{l}\text { Klasifikasi } \\
\text { Kelas } \\
\text { Lereng }\end{array}$ & Keterangan & Nilai \\
\hline I & $0 \%-8 \%$ & Datar & 20 \\
\hline II & $8 \%-15 \%$ & Landai & 40 \\
\hline III & $15 \%-25 \%$ & Agak Curam & 60 \\
\hline IV & $25 \%-45 \%$ & Curam & 80 \\
\hline V & $>45 \%$ & Sangat Curam & 100 \\
\hline
\end{tabular}

Sumber: Menteri Pertanian No 83/KPTS/UM/11/1980 dan SK/KPTS/UM/1981

c) Erodibilitas (Cf3)

Perhitungan factor kepekanaan tanah erosi kelerengan lahan dibagi dalam kelas-kelas sebagai berikut:

Tabel 1 Sistem Skoring Kriteria Kelas Lereng

dinilai dalam bentuk kepekaan erosi tanah berdasarkan jenis tanah dengan indeks tingkat erosi. Menurut kepekaannya terhadap erosi, terbagi dalam beberapa kelas, yaitu: 
Tabel 2. Kriteria Kepekaan Erosi Menurut

\begin{tabular}{|l|l|l|l|}
\hline $\begin{array}{l}\text { Kelas } \\
\text { Tanah }\end{array}$ & Jenis Tanah & Keterangan & Nilai \\
\hline 1 & $\begin{array}{l}\text { Aluvial, Glei } \\
\text { Planasol, Hidromof } \\
\text { Kelabu, Literia Air } \\
\text { Tanah }\end{array}$ & Tidak peka & 15 \\
\hline 2 & Latosol & Agak peka & 30 \\
\hline 3 & $\begin{array}{l}\text { Brown Forest Soil, } \\
\text { Non Calcis Brown, } \\
\text { Mediteran }\end{array}$ & Kurang peka & 45 \\
\hline 4 & $\begin{array}{l}\text { Andosol, Laterit, } \\
\text { Grumosol, Podsol, } \\
\text { Podsolik }\end{array}$ & Peka & 60 \\
\hline 5 & $\begin{array}{l}\text { Regosol, Litosol, } \\
\text { Organosol, Renzina }\end{array}$ & Sangat Peka & 75 \\
\hline
\end{tabular}

Sumber: SK Menteri Pertanian No. 83/ KPTS/ UM/ 11/ 1980 dan No. 638/KPTS/UM/8/1981

d) Curah Hujan (Cf4)

Data yang diperoleh dari data sekunder. Berikut formulasi faktor koreksi curah

$$
Q=\frac{\sum \text { rata }- \text { rata bulan kering }}{\sum \text { rata }- \text { rata bulan basah }}
$$

Keterangan:

a. bulan kering adalah bulan dengan curah hujan $<60 \mathrm{~mm}$

b. bulan lembab adalah bulan dengan curah hujan $60-100 \mathrm{~mm}$

c. bulan basah adalah bulan dengan jumlah curah hujan $>100 \mathrm{~mm}$

Sehingga nilai keseluruhan variable biofisik diterapkan persamaan untuk memperoleh besarnya nilai RRC dengan rumus:

$$
R C C=P C C \times C f_{1} \times C f_{2} \times \ldots \times C f_{n}
$$

Keterangan:

$\begin{array}{ll}\text { RCC } & \text { : Daya dukung rill } \\ \text { PCC } & \text { : Daya dukung fisik } \\ \text { Cfn } & \text { : Faktor koreksi }\end{array}$

Besarnya faktor koreksi memiliki rumus sebagai berikut:

$$
\mathrm{Cf}_{\mathrm{n}}=1-\frac{M n}{M t}
$$

Keterangan:

Cfn : faktor koreksi

Mn : nilai variabel terhitung

Mt : nilai maksimum variabel terhitung

c. Daya Dukung Efektif (Effective Carrying

\section{Capacity/ECC)}

ECC merupakan jumlah maksimum wisatawan dalam penelitian ini, dengan adanya faktor manajemen (Management Capacity/MC) yaitu suatu hasil kombinasi daya dukung riil dengan kapasitas manajemen area wisata. Berikut rumus ECC, yaitu:

$$
E C C=R C C \times M C
$$

Keterangan:

ECC : daya dukung efektif

RCC : daya dukung rill 
MC : kapasitas manajemen area (management capacity)

Kapasitas manajemen wisata dapat dihitung dengan menggunakan rumus:

$$
M C=R n / R t \times 100 \%
$$

Keterangan:

Rn : jumlah staf pekerja aktif

Rt : jumlah staf keseluruhan

Tahap selanjutnya untuk penilaian daya dukung yaitu membandingkan PCC,RCC, ECC dengan jumlah kunjungan wisatawan per hari dengan ketentuan sebagai berikut:

$$
\mathrm{PCC}>\mathrm{RCC} \text { dan } \mathrm{RCC} \geq \mathrm{ECC}
$$

a) Jika nilai $\mathrm{PCC}>\mathrm{RCC}$ dan $\mathrm{RCC} \geq \mathrm{ECC}$ artinya daya dukung besar,

b) Jika nilai ECC > RCC > PCC artinya jumlah wisatawan telah melampaui batas daya dukung,

c) Jika nilai $\mathrm{PCC}=\mathrm{RCC}=\mathrm{ECC}$ artinya daya dukung optimal.

\section{HASIL DAN PEMBAHASAN}

Daya dukung / carrying capacity wisata merupakan analisis perhitungan daya dukung ((fisik, riil dan efektif) kapasitas jumlah

Tabel 3.Jumlah Wisatawan Mangrove Wonorejo Per Hari Kurun Waktu September-Desember 2019

\begin{tabular}{|l|cccc|}
\hline Wisatawan & \multicolumn{4}{|c|}{ Bulan } \\
\cline { 2 - 5 } Per Hari & Januari & Februari & Maret & April \\
\hline Jumlah & 32619 & 33621 & 37809 & 37623 \\
\hline Rata-rata & 1087 & 1201 & 1260 & 1254 \\
\hline JKr & \multicolumn{4}{|c|}{$\mathbf{1 2 0 0}$} \\
\hline
\end{tabular}

Sumber: Analisis, 2019

\section{Analisis Daya Dukung Fisik (PCC)}

PCC merupakan jumlah maksimum wisatawan yang secara fisik terkecukupi oleh ruang yang disediakan pada waktu tertentu. PCC meliputi luas area wisata, luas area pengunjung per $\mathrm{m} 2$, dan faktor rotasi. Daya

$$
\begin{gathered}
P C C=A \times \frac{1}{B} \times R f \\
P C C=90000 \times \frac{1}{65 m^{2}} \times 2.6 \\
P C C=3510 \text { wisatawan/hari }
\end{gathered}
$$

Keterangan:

PCC: daya dukung fisik

A: luas area wisata mangrove $\left(\mathrm{m}^{2}\right)$

B: luas area wisatawan $\left(\mathrm{m}^{2}\right)$

Rf: rotation factor kunjungan/hari

Tabel 4. Nilai Daya Dukung Fisik/PCC Wisata Mangrove Wonorejo

\begin{tabular}{lcccc}
\hline Area Wisata & $\begin{array}{c}\mathbf{A} \\
\left(\mathbf{m}^{\mathbf{2}}\right)\end{array}$ & $\begin{array}{c}\mathbf{B} \\
\left(\mathbf{m}^{\mathbf{2}}\right)\end{array}$ & $\begin{array}{c}\text { Rf } \\
(\mathbf{j a m})\end{array}$ & $\begin{array}{c}\text { Nilai PCC } \\
(\text { wisatawan/hr) }\end{array}$ \\
\hline Mangrove Wonorejo & 58.500 & 65 & 2.6 & 2282 \\
\hline Rekreasi & 31.500 & 65 & 2.6 & 1228 \\
\hline Jumlah & 90.000 & & & $\mathbf{3 5 1 0}$ \\
\hline
\end{tabular}

Sumber: Analisis, 2019 dukung fisik wisata mangrove Wonorejo meliputi area mangrove Wonorejo dan area rekreasi. Berdasarkan perhitungan $\mathrm{PCC}$ dan tabel nilai daya dukung/PCC wisata mangrove Wonorejo dapat dilihat sebagai berikut:

maksimum wisatawan per hari pada luas dan satuan waktu tertentu. Berdasarkan hasil perhitungan jumlah wisatawan per hari di wisata mangrove Wonorejo dapat dilihat pada 
Berdasarkan hasil perhitungan PCC maka diperoleh PCC sebesar 3510 wisatawan per hari dengan penjabaran luas area mangrove Wonorejo (A) sebesar $58.500 \mathrm{~m}^{2}$, area rekreasi wisatawan (B) sebesar $65 \mathrm{~m}^{2}$ dan faktor rotasi sebesar 2.6 jam, jika dikaitkan dengan jumlah rata-rata kunjungan wisatawan aktual per hari sebesar 1200 wisatawan per hari, maka telah terkecupi dari nilai daya dukung fisik dengan tetap memperoleh kepuasan.

2. Analisis Daya Dukung Riil (RCC)
Daya dukung riil merupakan perhitungan daya dukung sebenarnya dengan memperhitungkan faktor koreksi biotik abiotik (biofisik) sebagai faktor pembatas. Faktor biotik abiotik meliputi flora fauna, kelerengan, erodibilitas tanah, dan curah hujan. Perhitungan faktor koreksi biofisik sebagai berikut:

a. Perhitungan faktor biotik $\left(\mathrm{Cf}_{1}\right)$

Perhitungan faktor biotik wisata mangrove Wonorejo menggunakan perhitungan Indeks Diversitas Simpson (IDS). Berikut perhitungannya (Tabel 5)

Tabel 5 Jumlah dan Jenis Spesies Biotik Wisata Mangrove Wonorejo

\begin{tabular}{|c|c|c|}
\hline Spesies & ni & $\sum n i(n i-1)$ \\
\hline Mangrove & 21 & 420 \\
\hline Burung & 42 & 1722 \\
\hline Mamalia & 2 & 2 \\
\hline Invertebrata & 19 & 342 \\
\hline Ikan & 3 & 6 \\
\hline Herpetofauna & 4 & 12 \\
\hline Total & $\mathrm{N}=91$ & 2504 \\
\hline \multicolumn{3}{|c|}{$\mathrm{N}(\mathrm{N}-1)=\mathbf{8 1 9 0}$} \\
\hline
\end{tabular}

Sumber: Analisis 2019

b. Perhitungan faktor kelerengan $\left(\mathrm{Cf}_{2}\right)$

Perhitungan kelerengan ini berdasarkan hasil data sekunder, dimana area wisata mangrove Wonorejo memiliki kelas lereng 0-2\% dengan skor nilai 20 yang memiliki area datar secara umum. Skor nilai tersebut selajutnya ditetapkan sebagai nilai
$\mathrm{M}_{\text {kelerengan }}$ dan nilai maksimum Mt adalah 100, sehingga diperoleh nilai faktor $\mathrm{Cf}_{2}$ sebesar 0.8. Penilaian dilakukan dengan menggunakan system skoring pada kriteris kelas lereng pada berdasarkan peraturan yang tersedia. Perhitungan koreksi $\mathrm{Cf}_{2}$ sebagai berikut:

Keterangan:

$$
\begin{aligned}
& C f 2=1-\frac{20}{100} \\
& C f 2=0.8
\end{aligned}
$$

Cfn : faktor koreksi

Mn : nilai variabel terhitung

Mt : nilai max variabel terhitung

c. Perhitungan faktor erodibilitas (Cf3)

Faktor koreksi erodibilitas tanah (Cf3) yang diketahui melalui data sekunder yang kemudian dibandingkan dengan SK Menteri Pertanian No.837/KPTS/UM/ 11/1980 dan No.638/KPTS/UM/8/1981 tentang kriteria kepekaan erosi menurut jenis tanah, yaitu jenis tanah Gromosol di area wisata mangrove Wonorejo dengan nilai indeks kepekaan tanah sebesar 60 (ditetapkan sebagai Merodibilitas) dan nilai Mt adalah 75, sehingga diperoleh nilai faktor koreksi erodibilitas tanah $\left(\mathrm{Cf}_{3}\right)$ adalah 0.2 . Perhitungan koreksi $\left(\mathrm{Cf}_{3}\right)$ sebagai berikut:

$$
\begin{gathered}
C f 3=1-\frac{M n}{M t} \\
C f 3=1-\frac{60}{75} \\
C f 3=0.2
\end{gathered}
$$


Keterangan:

Cfn : faktor koreksi

Mn : nilai variabel terhitung

Mt : nilai max variabel terhitung

d. Perhitungan curah hujan (Cf4)

Faktor koreksi curah hujan pada tahun 2018 diperoleh jumlah bulan basah dan bulan kering

untuk menghitung Indeks Curah Hujan (Q) adalah 47 bulan kering dan bulan 254 bulan basah. Perhitungan indeks curah hujan sebagai berikut:

$$
\begin{gathered}
Q=\frac{\sum \text { rata }- \text { rata bulan kering }}{\sum \text { rata }- \text { rata bulan basah }} \\
Q=\frac{47}{254} \\
Q=0.185
\end{gathered}
$$

Indeks curah hujan $(\mathrm{Q})$ sebesar 0.185 yang kemudian ditetapkan $\mathbf{M}_{\text {curahhujan }}$ dan $\mathrm{Mt}$ sebesar 7 (nilai indeks tertinggi dalam klasifikasi Schmidt-Ferguson), sehingga faktor koreksi $\left(\mathrm{Cf}_{4}\right)$ sebesar 0.974 yang termasuk dalam kategori bersifat iklim sedang. Perhitungan RCC adalah jumlah wisatawan yang

$$
\begin{gathered}
R C C=P C C \times C f_{1} \times C f_{2} \times C f_{3} \times C f_{4} \\
R C C=3510 \times 0.695 \times 0.8 \times 0.2 \times 0.974 \\
R C C=380 \text { wisatawan/hari }
\end{gathered}
$$

diperbolehkan berkunjung ke objek wisata dengan faktor koreksi atau CF yang diambil dari karakteristik objek yang ditetapkan pada PCC. Perhitungan RCC dan tabel nilai daya dukung riil wisata mangrove Wonorejo sebagai berikut:

Keterangan:
RCC : daya dukung riil
PCC : daya dukung fisik
$\mathrm{Cf}_{1} \quad$ : faktor koreksi biotik
$\mathrm{Cf}_{2}$ : kelerengan
$\mathrm{Cf}_{3} \quad$ : erodibilitas tanah
$\mathrm{Cf}_{4} \quad$ : curah hujan

Tabel 6 Nilai Daya Dukung Riil/RCC Wisata Mangrove Wonorejo

\begin{tabular}{|l|rrrrr|r|r|}
\hline \multirow{1}{*}{$\begin{array}{c}\text { Area } \\
\text { Wisata }\end{array}$} & \multicolumn{5}{|c|}{ Nilai Cfn } & Nilai & Nilai \\
\cline { 2 - 5 } & $\mathrm{Cf}_{1}$ & $\mathrm{Cf}_{2}$ & $\mathrm{Cf}_{3}$ & $\mathrm{Cf}_{4}$ & PCC & RCC \\
\hline $\begin{array}{l}\text { Mangrove } \\
\text { Wonorejo }\end{array}$ & 0.695 & 0.8 & 0.2 & 0.974 & 2282 & 247 \\
\hline Rekreasi & 0.695 & 0.8 & 0.2 & 0.974 & 1228 & 133 \\
\hline Jumlah & & & & & 3510 & $\mathbf{3 8 0}$ \\
\hline
\end{tabular}

Sumber: Analisis, 2019

Berdasarkan hasil perhitungan nilai RCC pada kondisi faktor biofisik yang cukup membatasi jumlah wisatawan adalah faktor biotik (flora fauna) yang memiliki level sedang sebesar 0.695, yaitu keberagaman flora fauna cukup stabil. Nilai daya dukung riil/RCC wisata mangrove Wonorejo sebesar 380 wisatawan per hari, sehingga mampu

menampung jumlah kunjungan wisatawan per harinya

3. Analisis Daya Dukung Efektif (ECC)

Analisis daya dukung efektif ini fokus pada jumlah kunjungan maksimum dimana objek tetap lestari pada tingkat manajemen yang tersedia. Perhitungan kapasitas manajemen dapat dilihat sebagai berikut:

$$
\begin{aligned}
& M C=R n / R t \times 100 \% \\
& M C=18 / 28 \times 100 \% \\
& M C=64.28
\end{aligned}
$$




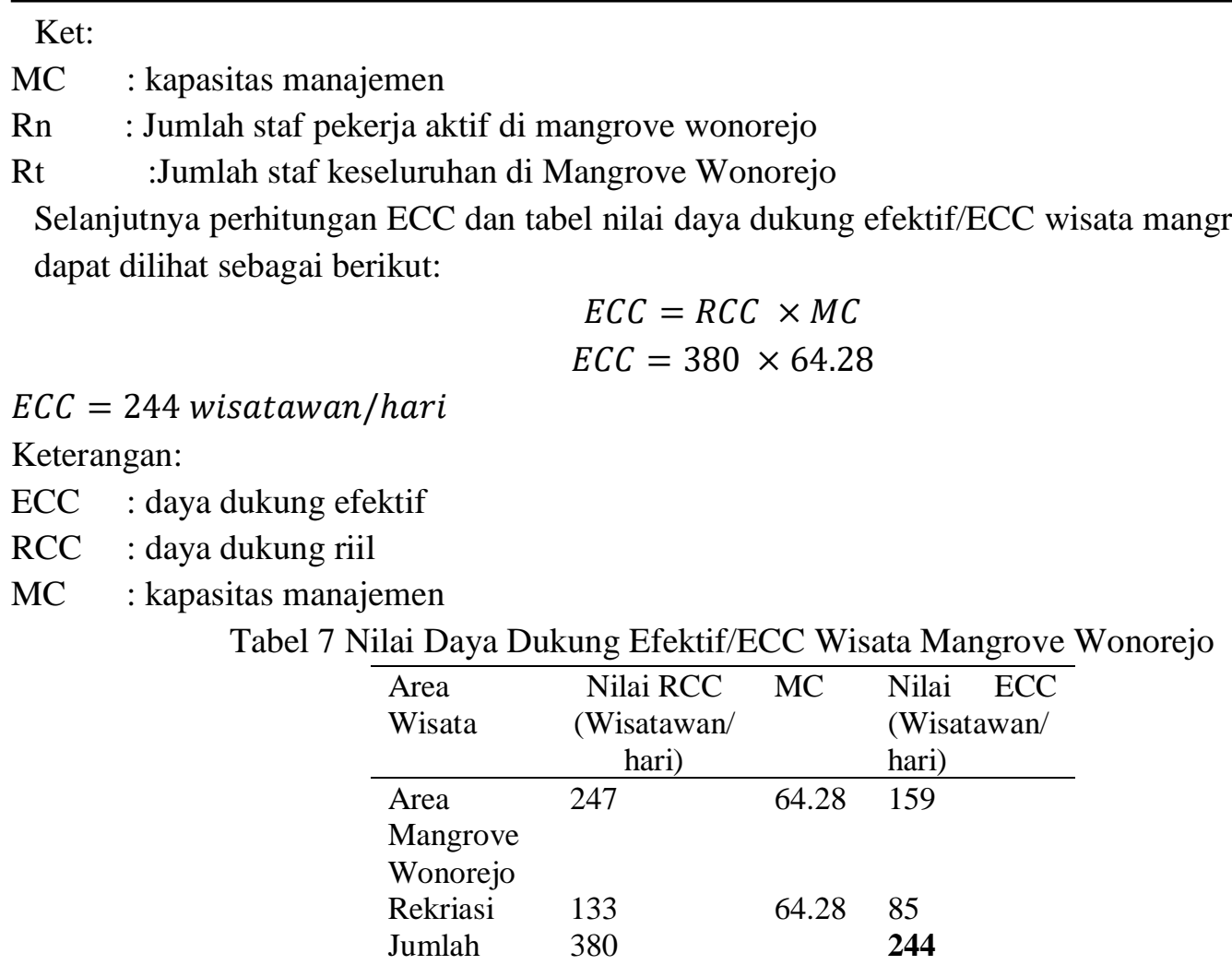

Sumber: Hasil Analisa, 2019

Berdasarkan nilai ECC yang dikaitkan dengan kapasitas manajemen/MC memperoleh nilai ECC sebesar 244 wisatawan per hari atau masih dibawah jumlah kunjungan aktual per hari, dengan nilai MC sebesar $64.28 \%$.

$$
P C C>R C C \geq E C C
$$

Atau $\quad 3510>380 \geq 244$, yang artinya kawasan wisata mangrove Wonorejo masih dapat menampung kunjungan wisatawan wisata mangrove Wonorejo.

\section{KESIMPULAN}

Tempat wisata menjadi salah satu tempat unggulan di Kota Surabaya karena memiliki sifat sebagai aktivitas hiburan. Mangrove Kota Surabaya sebagai salah satu wisata alam dan dikenal sebagai ekowisata. Pada tahun 2017-2018 mengalami peningkatan sebesar 2,9\%. Hal ini tentunya membutuhkan penilaian daya dukung yang dilihat dari tiga aspek yaitu fisik (PCC), riil (RCC) dan efektif (ECC). Hasil analisis ini menunjukkan bahwa daya dukung Mangrove Wonorejo Surabaya memiliki persamaan
Sehingga berdasarkan hasil analisis dapat disimpulkan bahwa daya dukung wisata Mangrove Wonorejo memiliki persamaan

PCC $>$ RCC $\geq$ ECC atau $3510>380 \geq$ 244 , yang artinya kawasan wisata mangrove Wonorejo masih dapat menampung kunjungan wisatawan wisata mangrove Wonorejo.

\section{UCAPAN TERIMAKASIH}

Ucapan terimakasih disampaikan oleh penulis kepada seluruh civitas akademika Universitas PGRI Adi Buana Surabaya Program Studi Perencanaan Wilayah dan Kota beserta mahasiswa bersangkutan.

\section{REFERENSI}

Cerina et al., (2011) dalam Strategi Optimasi Wisata Massal Di Kawasan Konservasi Taman Wisata Alam Grojogan Sewu

Dinas Ketahanan Pangan dan Pertanian Kota Surabaya (DKPP).2019. Jumlah dan 


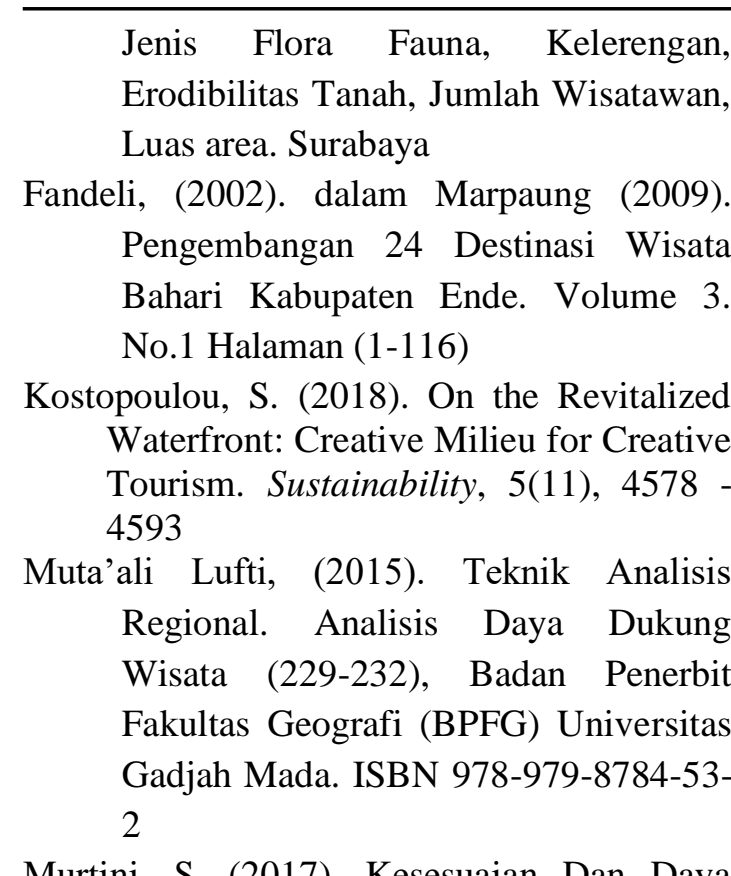

Murtini, S. (2017). Kesesuaian Dan Daya Dukung Ekowisata Mangrove Wonorejo Kota Surabaya. Pengelolaan Potensi Maritim Indonesia, 220-227. Surabaya.

Nurdin, M. (2011). Wisata Hutan Mangrove Wonorejo: Potensi Ecotourism dan
Edutourism Di Surabaya. Jurnal Kelautan, 4(1), 11-17.

Umam, K., Tjondro Winarno, S., \& Sudiyarto, S. (2015). Strategi Pengembangan Ekowisata Mangrove Wonorejo Surabaya. AGRARIS: Journal of Agribusiness and Rural Development Research, 1(1), 38-42. https://doi.org/10.18196/agr.116

Wahyuni, S., Sulardiono, B., \& Hendrarto, B. (2015). Strategi Pengembangan Ekowisata Mangrove Wonorejo, Kecamatan Rungkut Surabaya. Diponegoro Journal of Maquares, 4(4), 66-70. Retrieved from www.ejournals1.undip.ac.id/index.php/maquares/arti cle/download/9775/9496 